\title{
Acercamiento al análisis de John Rawls sobre la revolución o desobediencia civil
}

\author{
"Approach to John Rawls's analysis of revolution or \\ civil disobedience
}

\begin{tabular}{l} 
Adriana Vera Díaz \\
\hline Universidad Industrial de Santander \\
\hline
\end{tabular}

\section{Resumen}

A lo largo de la actividad intelectual de la época contemporánea, se da el interés de enfocar sus estudios al problema del derecho a la resistencia como uno natural, dando relevancia a la relación y diferencias con la potestad a la rebelión y la desobediencia civil; por ello, las diversas perspectivas se pueden catalogar de acuerdo con las diferentes posiciones que han adoptado los autores conforme a sus temáticas, particularmente de Filosofía Política y del Derecho, en donde se analizan implicaciones jurídicas y el tratamiento filosófico ante la relación sistemática propia del contexto; entendiendo a su vez, al derecho de resistencia como un sistema de restricción legítima del poder de la máxima autoridad del Estado para proteger el bien común, este materializado en actos de justicia, y salvaguardar la libertad del pueblo. Por esta razón, en este escrito se abordarán los estudios en torno a la desobediencia civil del filósofo John Rawls.

Palabras clave: desobediencia civil, filosofía política, derecho a la resistencia, John Rawls, Estado.

\begin{abstract}
Throughout the intellectual activity of the contemporary era, there is interest in focusing their studies on the problem of the right to resistance as a natural right giving relevance to the relationship and differences with the right to rebellion and civil disobedience; For this reason, the different perspectives can be classified according to the different positions adopted by the authors according to their themes, particularly political philosophy and law, where legal implications are analyzed and the philosophical treatment before the systematic relationship context; understanding in turn, the right of resistance as a system of legitimate restriction of the power of the highest authority of the State to protect the common good, this materialized in acts of justice and safeguard the freedom of the people. For this reason, this paper will address the studies on the civil disobedience of the philosopher John Rawls.
\end{abstract}

Keywords: civil disobedience, political philosophy, right to resistance, John Rawls, state.

Cómo citar este artículo:

Vera Díaz, A. (2019). Acercamiento al análisis de John Rawls sobre la revolución o desobediencia civil. Revista Amauta, 1734), 43-54. DOl: http://dx.doi.org/10.15648/am.34.2019.5
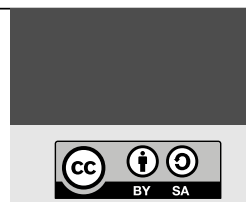

(C) 2019

Correspondencia de autor:

cony877@hotmail.com

Recibido:

18/Marzo/2019

Aceptado:

2/Junio/2019

Publicado:

28/Junio/2019 
Mientras que en la ideología de la época moderna se transforma el derecho a la resistencia en un derecho natural, que se funda en el deber ${ }^{1}$ de conservar y alcanzar la libertad con la revolución como medio de lograr la restauración del poder junto con la gloria y la virtud que este conlleva, y continuando con la postura del deber y el actuar moralmente, establecido por el filósofo de la llustración, Immanuel Kant, John Rawls desarrolla su pensamiento de desobediencia civil en su texto Teoría de la Justicia, como un mecanismo para persuadir cambios en normativas e instituciones políticas, jurídicas y formas de organización social que el pueblo esté considerando como ilegítimas; de ahí que la desobediencia civil procure identificarse con los principios constitucionales de un Estado democrático ejerciendo la protesta apelando "al sentido de justicia de la mayoría de la comunidad" (Rawls, 1997, p.332); es decir, se invocan a ciertos valores que comúnmente se comparten por los ciudadanos, sin importar que el acto civilmente desobediente viole la misma Ley contra la que se está protestando.

Como Rawls (1997) señala, con esta elucidación se pretende mostrar el contenido de los principios del deber y de las obligaciones naturales de una sociedad ordenada, casi justa y democrática pero que, al mismo tiempo, ocurren graves violaciones de la justicia, de allí que el autor puntualiza que "El problema de la desobediencia civil, tal y como lo interpretaré, solo se produce en un Estado democrático más o menos justo para aquellos ciudadanos que reconocen y aceptan la legitimidad de la constitución. El problema es de un conflicto de deberes" (p.331). Entonces, dicho problema en la desobediencia se encuentra en la naturaleza del deber, pues está inmersa dentro de los conflictos que se presenten en el momento en que la obligación de cumplir la ley difundida por la jurisdicción, se contrapone al deber de oposición de la injusticia. Acá, el insubordinado enfrenta un dilema moral, porque al ser partícipe de una sociedad tiene la obligación de cumplir con las leyes proclamadas, pero también tiene la obligación moral de impedir la injusticia aunque dicha injusticia se encuentre estipulada en la Ley.

Rawls elabora una reconsideración del contrato social asegurando que las reglas básicas de la sociedad obedecen a cierta idea de justicia, la cual precisa la distri-

1 Recordemos que en Kant (2003), por debajo de la moral y de la Constitución Política no puede organizarse nada, pues el Derecho entraña un equilibrio entre la acción y la reacción, fruto de la Ley de la libertad. (Cfr. ¿Qué es ilustración?, p.275). 
bución de los beneficios de la cooperación social en la que se basa la concepción contractualista ${ }^{2}$ como la forma más apropiada para la construcción de un concepto de justicia como equidad (Mejía, 2005, p.29); además, al igual que Kant (2012) para quien: "Son injustas todas las acciones que se refieren al derecho de otros hombres cuyos principios no soportan ser publicados" (p.100), Rawls precisa de la idea de publicidad $^{3}$ en su constructo de contrato social, con el fin de garantizar la legitimidad de los principios de la justicia, pues estos últimos al ser públicos, conllevan a establecer que todos los sujetos tienen los conocimientos de los fundamentos que rigen una sociedad bien ordenada; de manera que los conflictos se pueden minimizar por medio de diferentes formas de los convenios que se fundamentan en el acuerdo de las partes, así mismo, en el sometimiento voluntario por ambos bandos o por enfrentamiento de las fuerzas.

No obstante, para el autor, en el contrato fundacional se renuncia a esto último mediante acuerdos de los mismos partícipes o representantes para transferir el acaparamiento legítimo de la autoridad en quien delegue la mísma, y así poder generar leyes que sean aplicables por otras autoridades que cuentan con el respaldo de la fuerza legal, quedando así, como único medio legítimo para resolver conflictos la negociación y la adjudicación, por tanto:

la desobediencia civil es un acto público. No sólo se dirige a principios públicos, sino que se comete en público. Se da a conocer abiertamente y con el aviso necesario, y no es encubierto o secreto. (...) Por esta razón, entre otras, la desobediencia civil no es violenta. Trata de no emplear la violencia, especialmente contra personas, no por una aversión del principio del uso de la fuerza, sino porque es expresión final del propio caso. La participación de actos violentos que probablemente causarían heridas y daños es incompatible con la desobediencia civil como medio de reclamación. (Rawls, 1997, pp.333-334)

2 "Rawls va a concebir un procedimiento de argumentación moral para garantizar que los principios de la justicia sean escogidos contractualmente, pero rodeando ese contrato de todas las garantías necesarias para que sea el de hombres racionales y morales que no contaminen con sus juicios egoístas la imparcialidad de los mismos" (Mejía, 2005, p.52).

3 "Reconozcamos que Rawls establece la condición de publicidad en aras de salvaguardar en la esfera pública, los derechos que tienen los ciudadanos de una sociedad bien ordenada, porque ésta al estar regida por principios conocidos no simplemente por unos cuantos sino por todos, han de conformarse formas de razonamiento que permitan evaluar conductas que le dan primacía a los intereses particulares, para poder reorientarlas hacia las que se guían por los intereses de todos" (Campo, 2017, p.72). Kant (2012) establece que no hay que considerar el principio de publicidad como un simple principio ético que concierne a la virtud, sino que también como un principio jurídico que afecta al derecho de los hombres (Cfr. p.100). 
Por lo cual, la resistencia en oposición al orden existente queda deslegitimada, considerándose como legítima solo en oposición a elementos casi justos de orden existente, que propende a corregir aspectos injustos dentro del orden político por medio de la figura de desobediencia civil (Cfr. Rawls, 1997, p.348), debido a que "la injusticia deliberada invita a la sumisión 0 a la resistencia. La sumisión produce el desprecio de aquellos que perpetúan la injusticia y confirma su intención, mientras que la resistencia rompe los lazos de la comunidad" (Rawls, 1997, p. 349). Retomando la idea de la cita anterior, de que la desobediencia civil no es violenta, ha de tenerse presente que la autoridad y la violencia, practicadas por una entidad política, buscan la obediencia; en consecuencia, la autoridad hace un llamado a aceptar la legislación desde el interior, esto es, desde la convicción al ser ejecutada por el poder, el cual tiene la envergadura para actuar de forma convencional; mientras que la violencia pretende una aceptación por medio de la coerción o de presiones al pueblo, ya sean físicas o mentales. También es cierto que una Ley que inspire en el pueblo autoridad no requiere de la violencia para que este se subordine.

En el caso de violencia ejercida por el ciudadano, más no por el Estado, es posible que se dé el castigo estipulado por la legislación sin oponerse o entablar resistencia puesto que, según Rawls (1997), el actuar siendo conscientes del castigo y aceptar el mismo, le ayuda a dar credibilidad a la causa que se persigue, como él mismo lo expresa:

Se viola la ley, pero la fidelidad a la ley queda expresada por la naturaleza pública y no violenta del acto, por la voluntad de aceptar las consecuencias legales de la propia conducta. Esta fidelidad a la ley ayuda a probar a la mayoría que el acto es políticamente consciente y sincero, y que va dirigido al sentido de la justicia de la colectividad. (...) No cabe duda de que es posible imaginar un sistema legal en el que la creencia consciente de que la ley es injusta sea aceptada como justificación de la desobediencia. (...) Debemos pagar un precio para convencer a los demás de que nuestras acciones tienen, según nuestra opinión bien considerada, una base moral suficiente en las convicciones políticas de la comunidad. (p.334) 
Se hace necesario aclarar que este rasgo de no violencia no se encuentra relacionado a principios religiosos o pacifistas, pues, no es necesario estar ligado a ellos para desempeñar el rechazo de conciencia ${ }^{4}$ y la desobediencia civil de manera no violenta, aunque se pueden establecer ciertas excepciones en cuanto a los actos no violentos, ya que nuestro autor propone que si las instituciones estatales no prestan atención a las argumentaciones de aquellos que ejecutan la desobediencia civil, estimarían justificados algunos actos violentos pues los hacen para llamar su atención, es más, el hecho de acogerse a la desobediencia civil no implica renunciar de manera definitiva a la idea de resistencia violenta, en miras de que en repetidas ocasiones han ignorado la apelación en contra de la injusticia, la mayoría manifiesta su intención de incitar a la resistencia o sumisión, justificándose en una normativa democrática.

Llegado a este punto cabe realizar la siguiente pregunta: ¿en definitiva, qué es entonces la desobediencia civil? Rawls (1997) nos define la desobediencia civil como "un pacto público, no violento, consciente y político, contrario a la ley, cometido habitualmente con el propósito de ocasionar un cambio en la ley o en los programas de gobierno" (p.332). Existen para el autor dos tipos de desobediencia civil: una directa, en la cual la violación de una norma jurídica es considerada en sí misma como injusta; y la otra, indirecta, la cual desobedece leyes en sí misma válidas con el fin de protestar y plantear el propio caso cuando no hay forma de quebrantar los programas de gobierno impugnados directamente. En otras palabras, si la legislación decreta una ley de política exterior, no necesariamente se requiere una acción de hecho de esta naturaleza.

Para el autor en cuestión, en este sistema se quiere llamar la atención de las mayorías sobre una norma que implica arbitrariedad para las minorías o para contrariar los principios políticos o de justicia; sin embargo, esa desobediencia no debe trasgredir los derechos de los demás, pues eso sería contradictorio con el impulso ético de mejorar el sistema. Para que la desobediencia civil sea legítima, Rawls instaura una serie de condiciones como: la desobediencia debe tratarse de una causa justa, debe ir en contra de injusticias sustanciales y claras; además debe de tener una intencio-

4 John Rawls (1997) desglosa este concepto en el acápite 56 titulado "La Definición de Rechazo de Conciencia", esta se basa en "obedecer un mandato legislativo más o menos directo, o una orden administrativa". Sigue señalando que se considera rechazo, pues al dársenos una orden, y considerando la naturaleza de la situación, la aceptación de nuestra parte es bien conocida por las autoridades (Cfr. p.335). 
nalidad recta y apelar a esta como último recurso, es decir, una vez agotadas las vías legales, fuesen inútiles o ineficientes; y finalmente, las acciones que se planteen deben guardar proporción con las acciones que las originan, además de evaluarse prudentemente las secuelas sociales factibles porque "el ejercicio del derecho a la desobediencia civil, como cualquier otro derecho, ha de ser racionalmente proyectado para conseguir nuestros fines o los de quienes deseamos proteger" (Rawls, 1997, p.342).

Dentro del constructo teórico del filósofo no podemos encontrar explícito en quién recae la autoridad legítima, aunque en Rawls la soberanía comisionada vuelve al ciudadano cuando viola su propia razón de ser, dicha razón de ser es aprovechar los beneficios de la cooperación en una marco de igual libertad y oportunidades. En otros términos, la resistencia ya no es entendida como la oposición a un sistema injusto con el fin de derrocarlo, sino que bajo el supuesto de que el sistema liberal es "el más justo posible", la resistencia, entonces, queda relegada a un conflicto interno de intereses y apunta al mejoramiento del contrato social, la idea es que la desobediencia es el eje central para la comprensión adecuada de los fundamentos morales de la democracia, que responden a la regla de la mayoría.

Así, entendida, la desobediencia civil es claramente distinta de la acción militante y la obstrucción; se aparta mucho de la resistencia violentamente organizada. El militante, por ejemplo, se opone mucho más profundamente al sistema político vigente, no lo acepta como casi justo o razonable, o bien cree que difiere ampliamente de sus principios declarados o que persigue una errónea concepción de la justicia. Mientras que su acción es consciente, según sus propias convicciones, no apela al sentido de justicia de la mayoría (...), pues cree que su sentido de la justicia es erróneo, o sin ningún efecto. En cambio, intenta, a través de actos militantes de perturbación, resistencia y similares, atacar la concepción prevaleciente de la justicia, o provocar un movimiento en la dirección deseada. (Rawls, 1997, pp. 334-335)

Por ende, para el autor, la desobediencia civil es el eje central para una comprensión apropiada de los fundamentos morales democráticos, ya que involucra las 
cuestiones naturales y los límites de las reglas de la mayoría, en la cual se amparan en decisiones públicas que son necesarias en un sistema, "Al justificar la desobediencia civil no apelamos a principios de moral personal 0 a doctrinas religiosas, aunque éstas pueden coincidir y apoyar nuestras demandas" (Rawls, 1997, p.333); es por eso que, se acogen en los principios de justicia, pues estos en el sistema jurídico son más idóneos en cuanto al acceso de las diferentes instituciones porque en dichas instituciones se elaboran constantemente deberes y obligaciones que permiten el accionar del sistema jurídico; no olvidemos que "el objeto primario de los principios de justicia social es la estructura básica de la sociedad, la disposición de las instituciones sociales más importantes de un esquema de cooperación" (Rawls, 1997, p.62). Desde el punto de vista kantiano estos principios de justicia son imperativos categóricos, que de acuerdo con Jesús Campo (2017), se interpretan como una tentativa de contrastarlos con circunstancias reales (Cfr. p.58):

La réplica de Kant sería que aunque actuar con base en un conjunto coherente de principios básicos sería el resultado de una decisión por parte del ego noumenal, no todas esas acciones del ego fenomenal expresan esta decisión como la de un ser libre y racional.(...) El objetivo principal de Kant es profundizar y justificar la idea de Rousseau de que la libertad consiste en actuar de acuerdo con una ley que nos damos a nosotros mismos. (Rawls, 1997, pp.239-240)

Entonces, los principios de justicia son aquellos que ayudan a acordar a los hombres racionales y libres en una posición original de igual libertad; esto, suministrado desde un velo de la ignorancia ${ }^{5}$, donde su función es imposibilitar que cualquiera de los integrantes en la posición original obtenga lograr unas ventajas personales 0 de grupo valiéndose de sus condiciones sociales, políticas, jurídicas o culturales; en consecuencia,

Mediante el velo de la ignorancia los sujetos son despojados de sus vinculaciones e intereses reales, planes de vida, concepciones particulares del bien; no conocen su lugar en la sociedad ni sus capacidades y habilidades. (...) se convierten, en la construcción, en seres racionales

\footnotetext{
$5 \quad$ Al hacer mención del velo de la ignorancia, Rawls en una nota al pie manifiesta que es una formulación implícita en la doctrina del imperativo categórico de Kant y por tanto este enfoque del parágrafo 24, es netamente interpretación kantiana de la condición natural (Cfr. Rawls, 1997, p.135).
} 
con autonomía racional, y morales con autonomía plena. (Cortés, 1999, p.23)

Entonces vemos que es así como:

El procedimiento IC ayuda a Rawls a construir su noción de persona libre, en la medida que este posibilita que un agente moral se autodetermine; es decir, que pueda darse una ley a sí mismo, manifestando la herencia kantiana de ser creador y legislador donde la consecuencia más significativa es la limitación de la autonomía. (Campo, 2017, p.58)

Siendo así, la interpretación normativa del individuo conlleva a una interpretación objetiva de la ley moral vinculada con la acción social, así como la relación que tiene con los propios fines; cabe recordar la aclaración que nos da Rawls, sobre que no debemos comprender el velo de la ignorancia como un constitutivo metafísico de la persona, "El velo de ignorancia evita el influjo de las contingencias de clase social y fortuna" (Mejía, 2005, p.34), por ello, "El propósito del velo de ignorancia es representar la igualdad de los seres humanos en tanto personas morales y asegurar que los principios no serán escogidos heterónomamente" (Mejía, 2005, p.53), por tanto:

El velo de la ignorancia... no tiene implicaciones metafísicas específicas acerca de la naturaleza del yo; no implica que el yo preceda ontológicamente a los hechos de cuyo conocimiento están eximidas las partes. Podríamos, por así decirlo, entrar en esa posición en cualquier momento limitándonos a razonar a favor de principios de justicia respetando las restricciones informativas mencionadas. (Rawls, 1996, p.57)

Lo anterior se asemeja, según Onfray (2011), a lo que Henry Thoreau pretendía en su análisis de la desobediencia civil, pues, para el filósofo estadunidense, esta se refiere a una revolución pacífica que ayuda a combatir los poderes exteriores que obstaculizan el gobierno de sí mismo; “Esa revolución supone dos hechos: la negativa a obedecer, la insumisión, la rebeldía ante el sometimiento y, lo que es más complicado, la dimisión del funcionario del que se supone que hace respetar la ley" (p.275). Para Thoreau (2008), es así como: "los gobiernos prueban cuán eficazmente los hombres se dejan imponer una autoridad, aun imponiéndosela a sí mismo para su 
propia ventaja" (p.15). Profundizar en los principios es clave para poder comprender la justificación de la desobediencia civil dentro de un marco de "teoría inacabada de justicia"6.

Es claro que, en una Constitución justa es posible que no todas sus leyes sean imparciales 0 , que incorpore de manera positiva a cada uno de los miembros de la sociedad; no obstante, en contraposición con dicha Constitución, las señaladas normas injustas serían las más destacadas, en esto, esa ley de mayorías puede concebir una afectación a las minorías fomentando los principios de justicia que Rawls va a tratar específicamente, es decir, de los principios de la libertad y de la igualdad, y de este modo, dar origen a la desobediencia civil y a la objeción de conciencia; en términos generales, se considera la desobediencia civil como algo político por el concepto de justicia invocada para recurrir a ella; en palabras del autor:

Ha de tenerse también en cuenta que la desobediencia civil es un acto político, no sólo en el sentido de que va dirigido a la mayoría que ejerce el poder político, sino también porque es un acto guiado y justificado por principios políticos, es decir, por los principios de justicia que regulan la constitución y en general las instituciones sociales. (Rawls, 1997, p.333)

Por consiguiente, la justicia recurre a ideales universalizables, de manera que pueda dar forma a una Constitución Política evitando a como dé lugar, el egoísmo con la exigencia que trae del mirar a los demás; a su vez, dicha desobediencia ha sido pensada para proteger a las minorías de las legítimas mayorías que, por el gran poder que poseen, pueden transgredir los derechos de estos; de ahí que al sentir dicha transgresión, les resulte factible accionar los instrumentos jurídicos tratando de modificar las normas que consideren le están afectando. En tal grado, se consideraría insólito que la mayoría recurriese a mecanismos de protección lícita.

Otro de los aspectos que Rawls señala en la desobediencia civil, es que es un hecho de conciencia, ya que esta no está únicamente compuesta por la razón, sino que también se desarrolla una conciencia en donde el sujeto, mediante las motivaciones racionales y no racionales decide realizar o no una acción, estimando a la conciencia

6 Rawls concibe una teoría no ideal de la justicia debido al impedimento de alcanzar una sociedad perfecta en lo jurídico; es asi que son reconocidos los errores y a su vez los métodos para enmendarlos, como último recurso, podemos encontrar la objeción de conciencia y la desobediencia civil. 
como gobierno del sujeto y, por tanto, con la potestad de decisión. Lo anterior se afianza desde la postura de Kant, cuando deja claro que por más delimitaciones naturales y del entorno que tengamos, el sujeto siempre podrá decidir su propio camino, debido a que para el filósofo prusiano, la última instancia que poseemos es la razón pura.

De tal forma que en la idea de Rawls (1997), si hemos de reconocer que las leyes injustas de alguna manera son obligatorias, siempre y cuando no excedan ciertos límites de la injusticia (Cfr. pp.306-355), es aquí, donde la conciencia es la que establece dichos límites de aceptación a esas leyes injustas; un ciudadano cuando se siente vulnerado en su conciencia, debe indicar dicho maltrato ante la comunidad por medio de una conducta sostenida, pues la conciencia es algo que se compone por aspectos racionales y no racionales que no se determinan gracias a los medios probatorios tradicionales; por lo que el ejercicio propio del rechazo de conciencia y de la desobediencia civil se encuentra en oposición de una normatividad específica más no de todo el orden constitucional, así, pues, "La desobediencia civil ha sido definida de modo que cabe entre la potestad legal y la creación de casos de prueba por una parte, y el rechazo consciente y las diferentes formas de resistencia por la otra" (Rawls, 1997, p.334).

Cierto es que aquellos que refutan o desobedecen civilmente, se mueven en el límite de la legalidad y la ilegalidad; lo primero, como forma protectora de los derechos que pudiesen proteger la conciencia, y lo segundo, manifestada en ir en contra de la Ley 0 el caso de no cumplirla. Para terminar esta exposición se hace necesario dejar claro que no necesariamente se le ha de exigir al desobediente un programa de cambio de normatividad o leyes alternas; al contrario, solo se le pide que tenga la intención de modificarla sobre la base de un discurso que demuestre desde la justicia, la manera en que la legislación lo afecta a él y a toda su comunidad. No olvidemos que la

desobediencia civil (lo mismo que la objeción de conciencia) es uno de los recursos estabilizadores del sistema constitucional, aunque sea, por definición, un recurso ilegal. (...), la desobediencia civil, utilizada con la debida moderación y sano juicio, ayuda a mantener y reforzar las instituciones justas". (Rawls, 1997, p.348

Así como lo expresa el filósofo al inicio del § 55 "esta teoría sólo fue planeada para el caso especial de una sociedad casi justa, una sociedad bien ordenada en su mayor parte, pero en la que, no obstante, ocurren graves violaciones de la justicia" (Rawls, 1997, p.331). 
Para finalizar, el derecho a la resistencia entendido como desobediencia civil, señala la diferencia de su postura clásica un carácter pacífico que tiende a perfeccionar todo el sistema democrático. Es así como Rawls, destaca el carácter constructivo de la desobediencia civil, limitado por los derechos de los demás, que no deben sentirse vulnerados en el ejercicio de la protesta; entonces, la desobediencia civil es el último recurso frente a las injusticias, que a pesar de ser un acto ilegítimo, no es de carácter delictivo pues se desarrolla en un marco jurídico. Asimismo, se señala que este tipo de protesta no pretende derrocar el Gobierno ni transformar la estructura civil básica. La desobediencia civil resulta entonces, como una figura que se opone a la democracia formal pero que encuentra su justificación en la concepción de democracia sustancial.

\section{Referencias bibliográficas}

Campo, J. (2017). Las huellas de Kant en el constructivismo político de John Rawls. Medellín, Colombia: Universidad Autónoma Latinoamericana, Ediciones Unaula.

Cortés, R. F. (1999). De la política de la libertad a la política de la igualdad. Un ensayo sobre los límites del liberalismo. Colombia: Instituto de Filosofía, Universidad de Antioquia.

Kant, I. (2012). Sobre la paz perpetua. Madrid, España: Alianza Editorial.

Kant, I. (2003). ¿Qué es ilustración? Y otros escritos de ética, política y filosofía de la historia. Madrid, España: Alianza Editorial, S.A.

Mejía, 0. (2005). La filosofía política de John Rawls: la teoría de la justicia de la tradición analítica a la tradición radical filosófico-política. Con Rawls y Contra Rawls. Una aproximación a la filosofía política contemporánea. Bogotá, Colombia: Universidad Nacional de Colombia. Recuperado de: http://www.bdigital.unal.edu. co/1261/3/04capi02.pdf

Onfray, M. (2011). Política del rebelde. Tratado de Resistencia e Insumisión. Barcelona, España: Editorial Anagrama, S.A.

Rawls, J. (1996). El liberalismo político. Barcelona, España: Crítica.

Rawls, J. (1997). Teoría de la justicia. México: Fondo de Cultura Económica.

Thoreau, H.D. (2008). El deber de la desobediencia civil. Medellín, Colombia: Editorial $\mathrm{Pi}$. 
